\title{
THE PRODUCTION OF BROMOPHENOLS RESULTING FROM THE CHLORINATION OF WATERS CONTAINING BROMIDE ION AND PHENOL
}

\author{
Janet A. SweEtman and Milagros S. Simmons \\ Department of Environmental and Industrial Health. The University of Michigan, Ann Arbor, \\ MI 48109, U.S.A.
}

(Received August 1979)

\begin{abstract}
The formation of 2,4,6-tribromophenol is shown to result from the chlorination of water containing phenol and bromide ion at pH 7.4. Direct bromination with hypobromous acid is compared with bromination by hypochlorous acid and bromide ion. Under conditions where $\mathrm{HOCl}$ is not limiting. a higher yield of bromine substitution products can be expected from bromination by $\mathrm{HOCl}+\mathrm{Br}^{-}$than by direct bromination by $\mathrm{HOBr}$.
\end{abstract}

\section{INTRODUCTION}

Much attention has been given to the formation of chlorinated organics, both volatile and non-volatile, during the treatment of natural waters with chlorine (Bellar et al., 1974; Carlson et al., 1975; Glaze \& Henderson, 1975; Jolley, 1975; Symons et al., 1975; Glaze et al., 1976; Jolley et al., 1976; Kopperman et al., 1976; Rook, 1976).

The formation of volatile brominated organics (bromoforms and mixed haloforms) has also been rocognized (Rook, 1974; Kissinger \& Fritz, 1976; Symons et al., 1975) and attributed to the action of chlorine on the bromide ion present in these waters (Rook, 1974; Morris, 1976):

$$
\mathrm{HOCl}+\mathrm{Br}^{-} \rightarrow \mathrm{HOBr}+\mathrm{Cl}^{-} .
$$

Although bromide levels are generally low, $0.2 \mathrm{ppm}$ (Bowen, 1966), $0.1 \mathrm{ppm}$ (Simmons and Sweetman, 1977) levels as high as $2.2 \mathrm{ppm}$ have been reported (Houghton, 1946). Recent droughts in California have demonstrated that salt water, containing $65 \mathrm{ppm} \mathrm{Br}^{-}$, can enter into drinking water sources, enhancing natural bromide levels (Rasmussen, 1977). Wastewaters from the photographic industry may be a source of bromide, as well as anti-knock additives in gasoline (Rook, 1975).

Brominated phenols, indoles and anisoles formed from precursors during $\mathrm{BrCl}$ disinfection of wastewater effluent, have been identified in fish by Kuehl $e t$ al. (1978). In separate experiments he has shown that some of these brominated compounds readily bioaccumulate.

Chlorinated phenols have often been detected in treated wastewaters (Burttschell et al., 1959; Morris, 1975; Murphy et al., 1975; Rockwell \& Larson, 1978). It is possible that brominated phenols could be formed during the chlorination process if bromide is present in the chlorinating water. This study investigates chlorine-induced bromination using phenol as a model compound.

\section{MATERIALS AND METHODS}

\section{Reagents}

The water used was acid-distilled to remove ammonia. Aqueous phenol was prepared from redistilled analytical grade liquified phenol. The phenol concentration during all reactions was 1 ppm. Hypochlorous acid was generated by bubbling chlorine gas through water. Hypobromous acid was produced by adding elemental bromine to water. The reagents were standardized according to Standard Methods (1976). Potassium bromide was used as the source of the bromide ion. The phosphate buffer $(\mathrm{pH} 7.4)$ was made according to Standard Methods (1976).

\section{Apparatus \\ A Model 700 F \& M Laboratory Gas Chromatograph was used with a carrier gas of $95 \%$ argon, $5 \%$ methane, at a flow rate of approximately $60 \mathrm{ml} / \mathrm{min}$. An. electron capture detector with a tritium source (maximum temperature $225^{\circ} \mathrm{C}$ ) was used because of its high sensitivity for halo- genated compounds.}

Column I: $6 \mathrm{~mm}$ i.d. $\times 2 \mathrm{M}$ glass column packed with $4 \%$ Ultraphase SE $30+6 \%$ OV 210 on $80 / 100$ Chromosorb W.

Column II: $6 \mathrm{~mm}$ i.d. $\times 2 \mathrm{M}$ glass column packed with $3 \%$ OV 1 on $80 / 100$ Chromosorb $W$.

\section{Procedure}

Silylated Erlenmeyer flasks $(25 \mathrm{ml})$ were used for most reactions. Larger volumes were required for a mass spec. trometry analysis. Buffered phenol solution (pH 7.4) and various concentrations of $\mathrm{HOBr}$ or $\mathrm{HOCl}$ and $\mathrm{KBr}$ were added to a flask, the solution mixed, and the reaction timing begun. The ratios of $\mathrm{HOBr}$ : phenol or $\mathrm{HOCl}: \mathrm{KBr}$ :phenol were calculated on a molar basis. The reactions were stopped after 1 h contact time by the addition of excess sodium thiosulfate to destroy the $\mathrm{HOCl}$ and/or $\mathrm{HOBr}$ in the solution. The reaction products were concentrated using XAD-4 resin (Rohm \& Haas), derivatized with bistrimethylsilyl acetamide (BSA), and analyzed by electron capture GC as described by Prater et al. (1979).

Standard 2,4,6-tribromophenol solutions were made up in $20 \mathrm{ml}$ water buffered at pH 7.4 and carried through the same concentration and derivatization steps as the reaction volumes. The average recovery for these "water" standards, compared to standards of 2,4,6-tribromophenol made up directly in pyridine and derivatized with BSA, was $97 \%$. Standard curves of these water standards were prepared daily. Peak heights of the trimethylsilyl derivatives of 
Table 1. Bromination of phenol by hypobromous acid

\begin{tabular}{cc}
\hline HOBr:phenol & 24,6-tribromophenol (ppm) \\
\hline $10: 1$ & 1.5 \\
$8: 1$ & 2.0 \\
$4: 1$ & 1.0 \\
$2: 1$ & 0.2 \\
$1: 1$ & 0.1 \\
\hline
\end{tabular}

2,4,6-tribromophenol were utilized for quantitation. Linear regressions of these standard curves gave correlation coeffcient values, $r \geq 0.987$.

\section{RESULTS AND DISCUSSION}

Direct bromination with $\mathrm{HOBr}$ was tested at four ratios of $\mathrm{HOBr}$ :phenol $(\mathrm{HOBr}$ as measured is actually total free bromine, i.e. $\mathrm{HOBr}+\mathrm{OBr}^{-}$; $\mathrm{pK}=8.7$ ). The main product in all cases was 2,4,6-tribromophenol. In some cases small amounts of 2,4 and 2,6-dibromophenol, close to the limit of detection, were found. Table 1 shows the resulting concentrations of 2,4,6-tribromophenol. The amount of the 2,4,6-tribromophenol product decreased as the HOBr: phenol ratio was increased from 8:1 to $10: 1$. This may result from a further bromination product (e.g. pentabromophenol, which would not appear on the chromatogram under the conditions used), or may be due to ring cleavage (Moye \& Sternhell, 1966).

Chlorine-induced bromination, with equimolar amounts of hypochlorous acid (actually total free chlorine, i.e. $\mathrm{HOCl}+\mathrm{OCl}^{-}, \mathrm{pK},=7.5$ ) and $\mathrm{KBr}$ added, produced 2,4,6-tribromophenol. Table 2 shows that the amount of 2,4,6-tribromophenol increased with increasing $\mathrm{HOCl}$ and $\mathrm{KBr}$. No other products were found, indicating that the reaction $\mathrm{HOCl}+\mathrm{Br}^{-} \rightarrow \mathrm{HOBr}+\mathrm{Cl}^{-}$is much faster than the stepwise chlorination of phenol.

The identity of the 2,4,6-tribromophenol product produced by $\mathrm{HOCl}$ and $\mathrm{KBr}$ was first established by comparison of its retention time on two chromatographic columns, with the retention times of a 2,4,6-tribromophenol standard. Confirmation was provided by gas chromatography-mass spectrometry (AEI MS 30) on a "scaled up" reaction of HOCl: KBr:phenol (10:10:1).

Comparing Tables 1 and 2 shows that the extent of reaction at $\mathrm{pH} 7.4$ is less where the oxidation of $\mathrm{Br}^{-}$ to $\mathrm{HOBr}$ must precede the bromination of phenol. (Since the $\mathrm{pK}_{\mathrm{a}}$ of $\mathrm{HOCl}$ is 7.5 , the $[\mathrm{HOCl}] \simeq\left[\mathrm{OCl}^{-}\right]$ at $\mathrm{pH}$ 7.4. At a lower $\mathrm{pH}$ the reaction $\mathrm{HOCl}+\mathrm{Br}^{-} \rightarrow \mathrm{HOBr}+\mathrm{Cl}^{-}$would be expected to

Table 2. Chlorine-induced bromination of phenol by equimolar concentrations of $\mathrm{HOCl}$ and $\mathrm{KBr}$

\begin{tabular}{cc}
\hline HOCl:KBr:phenol & 2,4,6-tribromophenol (ppm) \\
\hline $10: 10: 1$ & 2.1 \\
$8: 8: 1$ & 1.9 \\
$4: 4: 1$ & 0.7 \\
$2: 2: 1$ & 0.02 \\
\hline
\end{tabular}

Table 3. Chlorine-induced bromination of phenol with excess $\mathrm{HOCl}$

\begin{tabular}{cc}
\hline HOCl:KBr:phenol & 2,4,6-tribromophenol (ppm) \\
\hline $5: 10: 1$ & 0.6 \\
$10: 5: 1$ & 1.8 \\
$5: 5: 1$ & 0.8 \\
$10: 1: 1$ & 0.3 \\
$5: 1: 1$ & 0.2 \\
\hline
\end{tabular}

proceed more rapidly.) Additional reactions were conducted with an excess of $\mathrm{HOCl}$ and one reaction with HOCl: KBr:phenol of 5:10:1 (Table 3). This last reaction shows the limiting effect of the $\mathrm{HOCl}$ concentration. The 2,4,6-tribromophenol produced is approximately that of the reaction 5:5:1. An excess of $\mathrm{HOCl}$ as expected increases the production of 2,4,6-tribromophenol. Indeed, the 2,4,6-tribromophenol is in excess of that found by the corresponding bromination with hypobromous acid. For example, with a tenfold excess of $\mathrm{HOCl}$ and equimolar concentrations of bromide and phenol, $0.3 \mathrm{ppm}$ of 2,4,6-tribromophenol was produced, as compared to $0.1 \mathrm{ppm}$ produced by direct bromination with equimolar concentrations of HOBr and phenol solution. This would be explained by some fraction of the HOBr participating in oxidation reactions with the phenol. The resulting bromide, while excess $\mathrm{HOCl}$ is present, can again be oxidized to $\mathrm{HOBr}$. This "recycling" of the $\mathrm{Br}^{-}$will be especially significant during the disinfection of natural waters, where the primary source of "chlorine demand" is for oxidation reactions (Jolley, 1973).

Where the hypochlorous acid was 5 to 10 times in excess of the $\mathrm{Br}^{-}$, chlorine substitution appears to have occurred. This is indicated by comparison of the reaction of $\mathrm{HOCl}$ :phenol $(10: 1)$, included as a control, with the above reactions. Figure 1 shows the products of the HOCl:phenol $(10: 1)$ reaction and the HOCl: $\mathrm{KBr}$ :phenol $(5: 1: 1$ and $10: 1: 1)$ reactions. The $\mathrm{HOCl}$ :phenol reaction produced two peaks (retention times [R.T.]: 2.2 and $3.2 \mathrm{~min}$ ). These peaks are assumed to represent chlorinated phenols. These peaks also appear in the two $\mathrm{HOCl}: \mathrm{KBr}$ : phenol reactions, indicating that there is enough excess $\mathrm{HOCl}$ to produce chlorinated products. A new peak (R.T.: $4.5 \mathrm{~min}$ ) is also present. This peak and the two "chlorination" peaks (R.T.: 2.2 and $3.2 \mathrm{~min}$ ) increased from the $5: 1: 1$ to $10: 1: 1$ (HOCl:KBr:phenol) reactions (the chromatograms shown are for difierent final volumes of concentrated products). The position of the peak (R.T.: 4.5 min) which is after the chlorination peaks (R.T.: 2.2 and $3.2 \mathrm{~min}$, after the dibromophenol peaks (R.T.: $2.8 \mathrm{~min}$ ) and before the 2,4,6-tribromophenol (R.T.: $6.2 \mathrm{~min}$ ), suggests a mixed bromochlorophenol, possibly a dibromochlorophenol.

\section{CONCLUSIONS}

This study suggests that chlorination, bromination and mixed halogenation products could be expected 

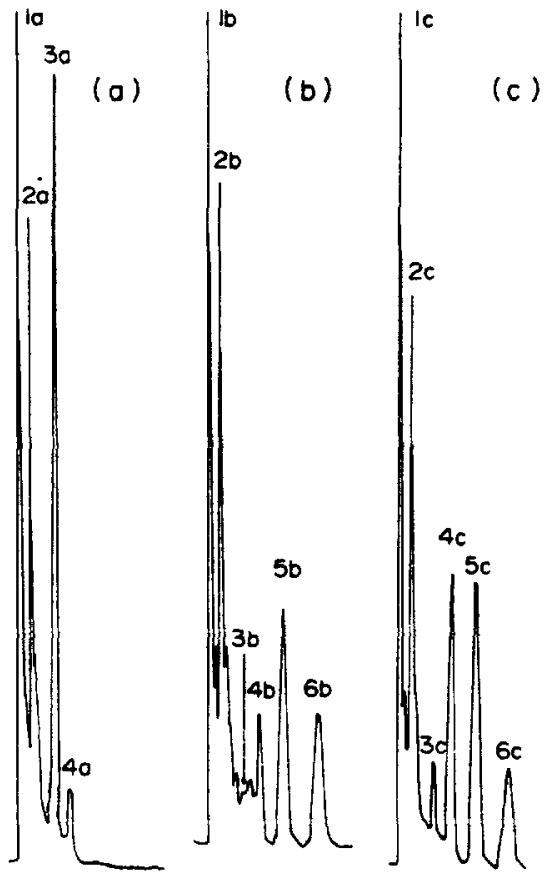

Fig. 1. (A) Gas chromatogram of products from the reaction of $\mathrm{HOCl}$ and phenol $(10: 1)$. (1a) and (2a) solvent peaks. (3a) chlorinated product (retention time $2.2 \mathrm{~min}$ ), (4a) chlorinated product (retention time $3.2 \mathrm{~min}$ ). (B) Gas chromatogram of products from the reaction of $\mathrm{HOCl}$, $\mathrm{KBr}$, and phenol $(5: 1: 1)$. (1b) and (2b) solvent peaks, (3b) chlorinated product (retention time $2.2 \mathrm{~min}$ ), (4b) chlorinated product (retention time $3.2 \mathrm{~min} /(5 \mathrm{~b})$ is suggested to be a bromochlorophenol (retention time $4.5 \mathrm{~min}$ ), (6b) 2,4,6 tribromophenol peak (retention time $6.2 \mathrm{~min}$ ). (C) Gas chromatogram of products from the reaction of $\mathrm{HOCl}$, $\mathrm{KBr}$, and phenol $(10: 1: 1)$. Identity of peaks $1 \mathrm{c}-6 \mathrm{c}$ the same as described above for $1 \mathrm{~b}-6 \mathrm{~b}$. Column: $4 \%$ SE-30 and $6 \%$ OV 210 , isothermal at $181^{\circ} \mathrm{C}$.

upon chlorination of waters containing bromide ion. The extent of formation of the chlorinated organics during water treatment can also be affected by the presence of ammonia in the water. This is attributed to the rapid formation of chloramines, which do not react to the same extent as does HOCl (Jolley, 1975). Morris (1976) has found that the reaction of $\mathrm{HOCl}$ with $\mathrm{Br}^{-}$is faster than the reaction of $\mathrm{HOCl}$ with $\mathrm{NH}_{3}$ when the $\mathrm{pH}$ is below 7.8 and $\left[\mathrm{Br}^{-}\right]=\left[\mathrm{NH}_{3}\right]$. In waste water effluent $\mathrm{HOBr}$, chloramines, and bromamines, singly or in combination, may be formed, depending on the $\mathrm{pH}$ and concentration of $\mathrm{NH}_{3}$ and $\mathrm{Br}^{-}$(Inman \& Johnson, 1978). Phenol can serve as a useful model compound to test if bromination occurs. during the chlorination of wastewaters containing high concentrations of bromide and ammonia.

Chlorination in the presence of bromide ion will likely produce largely brominated products where $\left[\mathrm{Br}^{-}\right]$approaches the free chlorine dose or mixed halogenation products where the $\left[\mathrm{Br}^{-}\right]$is small. $\mathrm{A}$ high yield of bromine substitution is the result of recycling of bromide while $\mathrm{HOCl}$ remains until a stable reaction product results. Bromide ion concen- tration should not be ignored as a water quality parameter.

\section{REFERENCES}

Bellar T. A., Lichtenberg J. J. and Kroner R. C. (1974) The occurrence of organohalides in chlorinated drinking waters. J. Am. Water Works Ass. 66, 703-706.

Bowen H. J. M. (1966) Trace Elements in Biochemistry, pp. 134, 177. Academic Press, New York.

Burttschell R. H., Rosen A. A., Middleton F. M. and Ettinger M. B. (1959) Chlorine derivatives of phenol causing taste and odor. J. Am. Water Works Ass. 51, 205-214.

Carlson R. M., Carison R. E., Kopperman H. L. and Caple R. (1975) Facile incorporation of chlorine into aromatic systems during aqueous chlorination processes. Envir. Sci. Tech. 9, 674-675.

Glaze W. H. and Henderson J. E. (1975) Formation of organochlorine compounds from the chlorination of a municipal secondary effluent. J. Wat. Pollut. Control Fed. 47, 2511-2515.

Glaze W. H. Henderson J. E. and Smith G. (1976) Analysis of new chlorinated organic compounds formed by chlorination of municipal wastewater. In Proceedings, Conference on the Environmental Impact of Water Chlorination (Edited by Jolley R. L.) pp. 153-174. Oak Ridge National Laboratory, Oak Ridge, TN.

Houghton G. U. (1946) The bromide content of underground waters. Part I. Determination and occurrence of traces of bromide in water. J. Soc. Chem. Ind., Lond. 65, 277-280.

Inman G. W., Jr. and Johnson J. D. (1978) The effect of ammonia concentration on the chemistry of chlorinated seawater. In Water Chlorination Environmental Impact and Health Effects (Edited by Joljey R. L., Gorchev H. and Hamilton D. H., Jr.) Vol. 2, pp. 235-252. Ann Arbor Science Publishers, MI.

Jolky R. L. (1973) Chlorination effects on organic constituents in effluents from domestic sanitary sewage treatment plants. Oak Ridge National Laboratory Publication ORNL-TM-4290.

Jolley R. L. (1975) Chlorine-containing organic constituents in chlorinated effluents. J. Wat. Pollut. Control Fed. 47, 601-618.

Jolley R. L., Jones G., Pitt W. W. and Thompson J. E. (1976) Chlorination of organics in cooling waters and process effluents. In Proceedings, Conference on the Environmental Impact of Water Chlorination (Edited by Jolley R. L.) pp. 115-151. Oak Ridge National Laboratory, Oak Ridge, TN.

Kissinger L. D. and Fritz J. S. (1976) Analytical notesanalysis of drinking water for haloforms. J. Am. Water Works Ass. 68, 435-437.

Kopperman H. L., Kuehl D. W. and Glass G. G. (1976) Chlorinated compounds found in waste-treatment effiuents and their capacity to bioaccumulate. In Proceedings, Conference on the Environmental Impact of Water Chlorination (Edited by Jolley R. L.) pp. 327-344. Oak Ridge National Laboratory, Oak Ridge, TN.

Kuehl D. W. Veith G. D. and Leonard E. N.' (1978) Brominated compounds found in waste-treatment effluents and their capacity to bioaccumulate. In Water Chiorination Environmental Impact and Health Effects (Edited by Jolley R. L., Gorchev H. and Hamilton D. H., Jr.) Vol. 2, pp. 175-192. Ann Arbor Science Publishers, MI.

Morris J. C. (1975) Formation of halogenated organics by chlorination of water supplies. U.S. Environmental Protection Agency, EPA-600/1-75-002.

Morris J. C. (1976) The chemistry of aqueous chlorine in relation to water chlorination. In Proceedings, Conference on the Environmental Impact of Water Chlorination 
(Edited by Jolley R. L.) pp. 27-41. Oak Ridge National Laboratory, Oak Ridge. TN.

Moye C. J. and Sternhell S. (1966) The degradation of aromatic rings: the action of hypochlorite on phenols. Aust. J. Chem. 19, 2107-2118.

Murphy K. L., Zaloum R. and Fulford D. (1975) Effect of chlorination practice on soluble organics. Water Res. 9. 389-396.

Prater W. A., Simmons M. S. and Mancy K. H. (1979) Microanalysis of aqueous samples for phenols and organic acids. Submitted to Analytical Letters.

Rasmussen M. (1977) Concern for delta water quality. San Francisco Chronicle, 20 August issue.

Rockwell A. L. and Larson R. A. (1978) Aqueous chlorination of some phenolic acids. In Water Chlorination Environmental Impact and Health Effects (Edited by Jolley
R. L., Gorchev H. and Hamilton D. H., Jr.) Vol. 2, pp. 67-74, Ann Arbor Science Publishers, MI.

Rook J. J. (1974) Formation of haloforms during chlorination of natural waters. Water Treat. Exam. 23, 234-243.

Rook J. J. (1975) Bromierung organischer Wasserinhaltsstoffe als Nebenreaktion der Clorung. Vom Wasser 44, 57-67.

Rook J. J. (1976) Haloforms in drinking water. J. Am. Water Works Ass. 68, 168-172.

Simmons M. S. and Sweetman J. A. (1977) Environmental Organic Analysis Laboratory Standard Methods for the Examination of Water and Waste Water (1976) Amer. Publ. Hith. Ass., New York.

Symons J. M., Bellar T. A., Carswell J. K., DeMarco J. Krapp K. L., Robeck G. G., Seeger D. R., Sloccum C. J., Smith B. L. and Stevens A. A. (1975) National organics reconnaissance survey for halogenated organics. J. Am. Water Works Ass. 67, 634-647. 